\title{
Faecal immunochemical test for patients with 'high-risk' bowel symptoms: a large prospective cohort study and updated literature review
}

\author{
Helga E. Laszlo $\mathbb{D}^{1,8}{ }^{凶}$, Edward Seward ${ }^{1,2}$, Ruth M. Ayling ${ }^{3}$, Jennifer Lake ${ }^{3}$, Aman Malhi ${ }^{4}$, Clare Stephens ${ }^{1,5}$, Kathy Pritchard-Jones ${ }^{1,2,6}$, \\ Donna Chung ${ }^{1}$, Allan Hackshaw (ID ${ }^{4,8}$ and Michael Machesney ${ }^{3,7,8}$
}

(c) The Author(s) 2021

\begin{abstract}
BACKGROUND: We evaluated whether faecal immunochemical testing (FIT) can rule out colorectal cancer (CRC) among patients presenting with 'high-risk' symptoms requiring definitive investigation.

METHODS: Three thousand five hundred and ninety-six symptomatic patients referred to the standard urgent CRC pathway were recruited in a multi-centre observational study. They completed FIT in addition to standard investigations. CRC miss rate (percentage of CRC cases with low quantitative faecal haemoglobin [f-Hb] measurement) and specificity (percentage of patients without cancer with low $\mathrm{f}-\mathrm{Hb}$ ) were calculated. We also provided an updated literature review.

RESULTS: Ninety patients had CRC. At $\mathrm{f}-\mathrm{Hb}<10 \mu \mathrm{g} / \mathrm{g}$, the miss rate was $16.7 \%$ (specificity $80.1 \%$ ). At $\mathrm{f}-\mathrm{Hb}<4 \mu \mathrm{g} / \mathrm{g}$, the miss rate was $12.2 \%$ (specificity $73 \%$ ), which became $3.3 \%$ if low FIT plus the absence of anaemia and abdominal pain were considered (specificity $51 \%$ ). Within meta-analyses of 9 UK studies, the pooled miss rate was $7.2 \%$ (specificity $74 \%$ ) for $\mathrm{f}-\mathrm{Hb}<4 \mu \mathrm{g} / \mathrm{g}$.

DISCUSSION: FIT alone as a triage tool would miss an estimated 1 in 8 cases in our study (1 in 14 from meta-analysis), while many people without CRC could avoid investigations. FIT can focus secondary care diagnostic capacity on patients most at risk of CRC, but more work on safety netting is required before incorporating FIT triage into the urgent diagnostic pathway.
\end{abstract}

British Journal of Cancer (2022) 126:736-743; https://doi.org/10.1038/s41416-021-01653-x

\section{INTRODUCTION}

Colorectal cancer (CRC) is the second leading cause of cancer death [1]. Abdominal symptoms often result in people being referred for cancer investigations. In England for example, these symptoms are defined in a National Institute of Health and Care Excellence (NICE) guideline (NG12), and patients go through an urgent referral pathway and are seen by a specialist within 14 days [2]. In 2018/19 over 396,000 patients in England went through this pathway [3]. Most were investigated with colonoscopy, the gold standard for detecting CRC, high-risk adenoma (HRA) and inflammatory bowel disease (IBD). However, $<8 \%$ of patients with high-risk symptoms have CRC [4].

Faecal haemoglobin $(\mathrm{f}-\mathrm{Hb})$ has a higher predictive value than symptoms of colorectal disease [5-7], with potential use as a simple test among symptomatic patients to facilitate early diagnosis of CRC, and thus improve cancer survival [8].

Several studies from multiple countries have examined the faecal immunochemical test (FIT), which quantifies $\mathrm{f}-\mathrm{Hb}$ concen- tration, and its ability to reliably exclude CRC, HRA and IBD in asymptomatic (i.e. screening) populations [9-12], and symptomatic 'lower-' [13-19] and 'higher-' risk [8, 20-28] patient groups. A meta-analysis indicated that $\mathrm{f}-\mathrm{Hb}$ has a higher test performance than the urgent referral pathway for all significant colorectal disease, and that referral using FIT to triage the use of colonoscopy could be more cost-effective than direct referral to colonoscopy [29]. NICE encouraged further research [30].

A recent large study of FIT, involving 9822 symptomatic patients due to have a colonoscopy, found that at the lowest level of detection $(<2 \mu \mathrm{g} / \mathrm{g}), 3 \%$ of CRC cases were missed, while $65 \%$ of people without CRC were below this threshold [26]. Our paper has several purposes: to report the accuracy of FIT in another large contemporary study in the United Kingdom, to examine patient features that might improve accuracy and to perform an up-to-date literature review (including meta-analyses) of all studies to provide reliable estimates of the accuracy of FIT as a rule-out test.

${ }^{1}$ North Central London Cancer Alliance, 47 Wimpole Street, London W1G 8SE, UK. ${ }^{2}$ University College London Hospitals NHS Foundation Trust, 235 Euston Road, London NW1

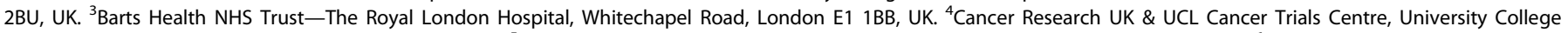

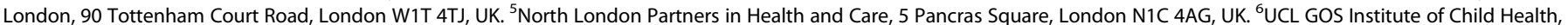

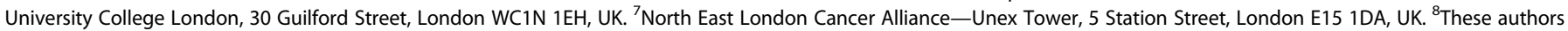
contributed equally: Helga E. Laszlo, Allan Hackshaw, Michael Machesney. ${ }^{\circledR}$ email: helga.laszlo@nhs.net

Received: 18 May 2021 Revised: 21 October 2021 Accepted: 23 November 2021

Published online: 13 December 2021 


\section{METHODS}

\section{Study design}

We conducted a prospective multi-centre observational study (qFIT study) which recruited patients from 24 hospitals in England and 59 general practices in London between April 2017 and March 2019. Sites were invited through the National Institute for Health Research Clinical Research Network (NIHR CRN); (Supplementary Table 1). National ethical approval was granted. The study was conducted following the STARD 2015 guideline for diagnostic studies [31].

Adult patients presenting with abdominal symptoms and urgently referred for suspected CRC and all patients who met the NICE NG12 referral criteria were eligible. People under 16 years of age or those unable to understand instructions (including non-English speakers who did not have an interpreter) were not invited.

Patients on the urgent referral pathway were offered a FIT pack (containing the specimen collection device, a patient experience survey and an information booklet outlining the study purpose). They were asked to take a single sample at their next bowel movement, before completing bowel preparation for colonoscopy or other examination and post it without delay to a central laboratory (Supplementary Fig. 1). By returning the FIT specimen collection device and attached paperwork, the patient provided implied consent to participate. Patients were aware that the FIT result was for research purposes only and that they would not be informed of the result.

\section{Sample analysis}

Faecal samples were taken with a specimen collection device and sent to the Clinical Biochemistry department at Barts Health NHS Trust by post. They were stored at $4{ }^{\circ} \mathrm{C}$ before analysis, which took place within 1 week of receipt and 2 weeks of sampling. The laboratory is accredited by the UK Accreditation Service to ISO 15189 standards. Analysis was performed using a single OC-Sensor ${ }^{\mathrm{TM}} \mathrm{iO}$ (Tokyo, Japan, Eiken Chemical Co., Ltd). Interrun imprecision was assessed with quality control materials (Eiken) in each run. Coefficients of variation were $2.8 \%$ at $14 \mu \mathrm{g} / \mathrm{g}$ and $3.0 \%$ at $91 \mu \mathrm{g} / \mathrm{g}$. External quality assurance was achieved via satisfactory performance in the relevant National External Quality Assurance Scheme. The lower limit of quantification was $4 \mu \mathrm{g} / \mathrm{g}$, with a coefficient of variation of $7.7 \%$. The upper analytical limit was $200 \mu \mathrm{g} / \mathrm{g}$ and samples with a concentration above this were not diluted and re-assayed, but reported as $>200 \mu \mathrm{g} / \mathrm{g}$. All laboratory analyses were performed blinded to patient characteristics and cancer outcomes.

\section{Outcomes}

CRC and other bowel pathologies were diagnosed by the participating sites, as per standard practice (BSG guidelines 2010 [32]) and examination outcomes were confirmed to the study team. Clinicians were blinded to the FIT result. Hospitals also provided copies of endoscopy, radiology and histology reports, clinic letters and referral forms to the study team for further data extraction and quality control checks. Incomplete patient records were followed up until November 2019.

\section{Statistical considerations}

We aimed to recruit at least 2200 patients to yield at least 80 CRC cases (assuming 3.5\% prevalence, based on previous studies [20, 21]), which would have an acceptable error rate around a sensitivity of $89 \%$ based on prior studies (i.e. $95 \%$ confidence interval (Cl) width of $\pm 6.8 \%$ ). Sensitivity, specificity, positive predictive value (PPV) and negative predictive value (NPV) were calculated as standard measures of test performance. For a cancer rule-out test, 100 minus sensitivity represents the proportion of CRC cases that would be missed by the test, and we label this the 'CRC miss rate', and refer to this instead of sensitivity. Both the CRC miss rate and specificity have a direct clinical consequence for patients and clinicians because they represent (respectively) harm (patients with CRC who would not have further investigations because their $\mathrm{f}-\mathrm{Hb}$ was below some threshold, so their cancer would not be found at the time) and benefit (patients without CRC who might not be referred for invasive cancer investigations). Effective rule-out tests must have a low cancer miss rate and ideally high specificity. Spearman's rank correlation and the Kruskal-Wallis test were used to assess associations between $\mathrm{f}-\mathrm{Hb}$ and age, sex and ethnicity. Fisher's exact test was used to assess differences in patient features between those with and without CRC cancer. STATA version 15 was used for all analyses [33].

\section{Meta-analyses}

Several studies have now reported the performance of FIT as a rule-out test for CRC among symptomatic patients. Formal systematic reviews [7, 29] have already been conducted on this topic that followed the Preferred Reporting Items for Systematic Reviews (PRISMA) guidance and one was funded by the UK NIHR Health Technology Assessment programme. We, therefore, used those reports and updated the literature review to find the most recent studies, using the PRISMA guidance. We performed metaanalyses to see where our own study fits in with others, but importantly to provide robust estimates of test performance that avoid under- or overestimating the cancer miss rate and specificity when based on individual studies. From PubMed we found a few studies published after the two previous reviews (up to 01 April 2021), using the following search terms: ("faecal immunochemical test" OR "fecal immunochemical test" OR "FIT" OR "faecal haemoglobin" OR "fecal hemoglobin") AND ("colorectal cancer" OR "CRC" OR "bowel") AND ("symptom*" OR "symptomatic") AND ("sensitivit"). AM reviewed and screened the titles and abstracts of articles retrieved in the search and determined eligibility by appraisal of full texts. As with the prior systematic reviews, we only included observational studies conducted in symptomatic patients and where the FIT result was not reported nor acted upon to manage patients.

Study characteristics and the CRC miss rate and specificity were extracted by $\mathrm{AM}$ and checked by $\mathrm{AH}$. Risk of bias or issues with applicability were determined through assessments of each study's methodology relating to patient selection, index tests, reference standards and patient flow and timing using the QUADAS-2 instrument for diagnostic studies. Exact $95 \% \mathrm{Cls}$ were calculated, and pooled estimates of the two endpoints were obtained by a standard random effects model using DerSimonian and Laird's method (in STATA) [33].

In one meta-analysis, we used data at the lowest available FIT cut-off using all studies, which was based on multiple $\mathrm{f}-\mathrm{Hb}$ thresholds (to be consistent with previous reviews). However, we focussed on the contemporary studies conducted in the United Kingdom since 2015, which had identified at least ten CRC cases, and where all patients had been referred onto the same national NG12 cancer pathway and therefore used the same criteria for selecting patients. In these UK studies, the FIT result was not reported back to clinicians or patients and therefore not used to manage patients.

\section{RESULTS}

Within the 2-year accrual timeframe, around 8000 FIT packs were distributed across sites and returned from 4676 patients. Among these, 3596 patients provided an evaluable faecal sample and the outcomes after cancer investigations were reported to the coordinating centre (Fig. 1). We did not have ethics approval to collect demographic data on patients who declined to return a FIT.

The median age was 67 years ( $70 \%$ aged $\geq 60$ years) and $53 \%$ were female (Table 1). The prevalence of the five most reported clinical features recorded on the urgent referral form was: change of bowel habit 1835 (51\%), rectal bleeding 970 (27\%), anaemia 684 (19\%), abdominal pain 427 (11.9\%) and weight loss 312 (8.7\%). The first investigation recorded for each patient was colonoscopy (77.7\%), CT colonography (14.2\%) and flexible sigmoidoscopy (7.5\%) (Supplementary Table 2).

The association between $\mathrm{f}-\mathrm{Hb}$ and each of age, sex and ethnicity are shown in Supplementary Figs. 2-4. The correlation coefficients and differences were not clinically meaningful.

\section{Clinical outcomes and FIT performance}

Ninety patients were diagnosed with CRC (2.5\%) and seven patients had cancers of another type. The most common diagnoses among patients without cancer were diverticulosis 1101 (31.5\%), polyps 805 (23\%), adenomas 623 (17.8\%), HRAs 61 (1.7\%), haemorrhoids $526(15 \%)$, and colitis $286(8.2 \%)$. Table 2 summarises the performance of FIT at different $\mathrm{f}-\mathrm{Hb}$ values. Data on IBD and advanced neoplasia will be reported separately.

At an $\mathrm{f}-\mathrm{Hb}$ cut-off of $<4 \mu \mathrm{g} / \mathrm{g}, 12.2 \%$ (95\% Cl 5.5-19.0) of CRC cases would be missed (1 in 8), but with a high specificity of $73 \%$ (95\% Cl 71.6-74.5). Using the cut-off of $<10 \mu \mathrm{g} / \mathrm{g}, 1$ in 6 CRC cases 


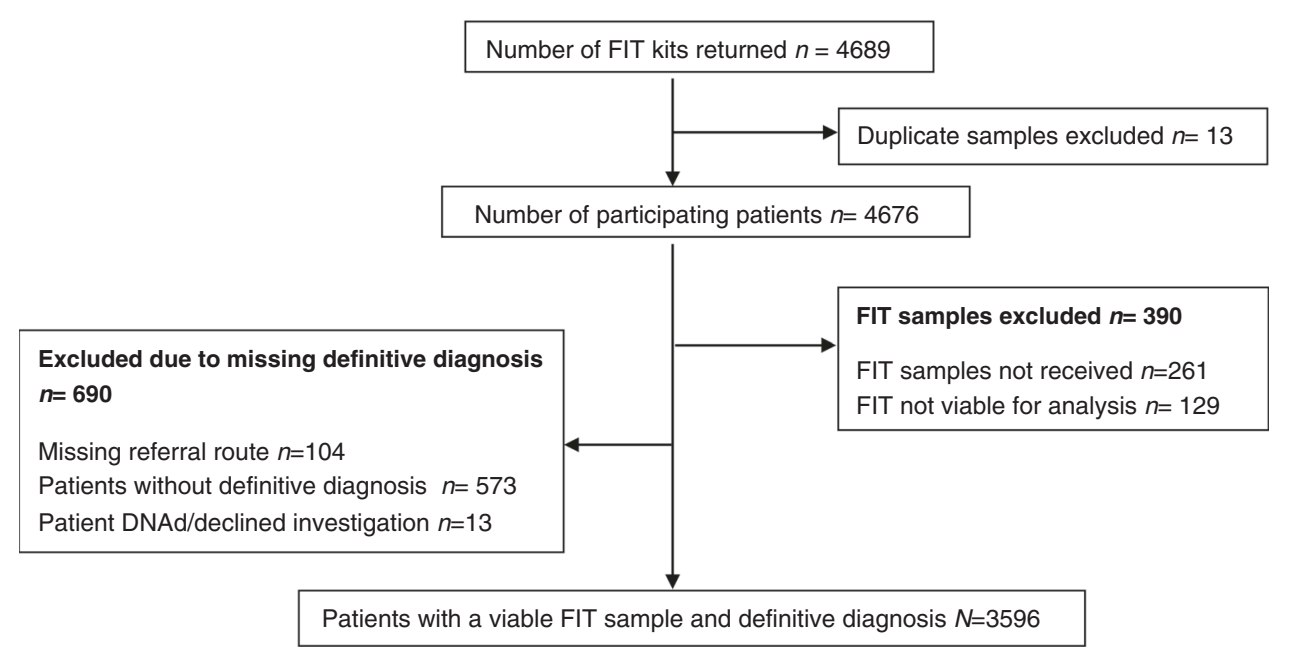

Fig. 1 qFIT study flow diagram.

would be missed $(16.7 \%, 95 \% \mathrm{Cl} 9.0-24.4)$ with a specificity of 80.1\% (95\% Cl 78.9-81.4).

When considering FIT to detect CRC (Table 2), the PPV is higher using either $\geq 4$ or $\geq 10 \mu \mathrm{g} / \mathrm{g}$ ( $7.7 \%$ or $9.7 \%$, respectively) than with the urgent referral pathway (2.5\%). Using $\mathrm{f}-\mathrm{Hb} \geq 10 \mu \mathrm{g} / \mathrm{g}$, the sensitivity, false-positive rate and PPV were $83.3 \%(95 \% \mathrm{Cl}$ 75.6-91.0), $19.9 \%$ (95\% Cl 18.6-21.1) and 9.7\% (95\% Cl 7.6-11.8), respectively. Increasing the threshold from $\geq 4$ to $\geq 10 \mu \mathrm{g} / \mathrm{g}$ is associated with a modest decrease in sensitivity from 87.8 to $83.3 \%$, and the false-positive rate decreases by 7.1 percentage points (from 27.0 to $19.9 \%$ ).

In our study, there were seven patients with cancer other than CRC (Supplementary Table 3). Five of these had $\mathrm{f}-\mathrm{Hb} \geq 4 \mu \mathrm{g} / \mathrm{g}$ : anal, prostate and neuroendocrine tumour and two with lymphoma, so they would have been found at that threshold following cancer investigations after the referral. Two cancers had $\mathrm{f}-\mathrm{Hb}<4 \mu \mathrm{g} / \mathrm{g}$ (neuroendocrine tumour and a lower rectal stromal tumour).

As we had found a relatively high CRC miss rate, we undertook exploratory (post hoc) analyses to investigate whether including clinical features could identify more patients with CRC. We examined the influence of patient symptoms when considered alongside the FIT test value. Among patients with $\mathrm{f}-\mathrm{Hb}<10 \mu \mathrm{g} / \mathrm{g}$, there was no association between the presence of CRC and either rectal bleeding or change in bowel habit (Table 3). However, CRC patients were more likely to present with abdominal pain and/or anaemia than non-cancer patients (66.7 vs. $29.4 \%, p=0.003$ ) (Table 3). Therefore, among all $90 \mathrm{CRC}$ cases, only 3 would be missed because their $\mathrm{f}-\mathrm{Hb}$ was $<10 \mu \mathrm{g} / \mathrm{g}$ and they did not have anaemia nor abdominal pain (miss rate 1 in 30; 3.3\% [3/90] and $95 \% \mathrm{Cl} 0-7.0)$. The corresponding specificity is $56 \%(1962 / 3499)$. Using the lowest cut-off ( $\mathrm{f}-\mathrm{Hb}<4 \mu \mathrm{g} / \mathrm{g}$ ) and absence of anaemia and abdominal pain, the miss rate is the same as with $10 \mu \mathrm{g} / \mathrm{g}$ (i.e. $3.3 \%)$ and specificity 51\% [1793/3499].

Patients with CRC and low FIT concentrations were also more likely to have multiple primary symptoms than non-cancer patients (Supplementary Table 4). Forty per cent of patients with CRC $(6 / 15)$ who had $\mathrm{f}-\mathrm{Hb}<10 \mu \mathrm{g} / \mathrm{g}$ presented with three or more of the symptoms listed in Table 3 , but $68.7 \%$ of patients without CRC (1926/2803) had none or only one of these symptoms $(p<$ $0.001)$. Similarly, $73.3 \%(11 / 15)$ of the CRC cases had two or three primary symptoms recorded (among anaemia, abdominal pain, rectal bleeding or abdominal pain), compared to only $18.6 \%$ (521/ 2803) of patients without CRC $(p<0.001)$.

Although the main purpose of using FIT as a triage tool is to help detect $C R C$, there is interest in finding people who have other bowel disorders such as IBD. Supplementary Table 5 shows FIT performance for detecting any cancer and IBD. At $\mathrm{f}-\mathrm{Hb}<4 \mu \mathrm{g} / \mathrm{g}$, $38.7 \%$ of all cases (all cancer types and IBD cases) could be missed. There were 213 cases of IBD in total, of which $50.2 \%$ had $\mathrm{f}-\mathrm{Hb}<4$ $\mu \mathrm{g} / \mathrm{g}$. Further details of FIT performance for pathology other than cancer will be reported separately.

\section{Literature review and meta-analyses}

Sixty-two articles were identified, of which 20 were considered for inclusion in our meta-analyses [8, 13, 15, 17-22, 25-28, 34-42]. One recently conducted study from the United Kingdom was excluded because the FIT result was used to select patients for referral to investigations, rather than being sent in parallel with the national cancer diagnostic pathway (the included contemporary UK studies did not act on the FIT result) [19]. Supplementary Tables 6 and 7 show the study characteristics and performance measures of all studies. Acknowledging the differences in laboratory methods, FIT assays and local cut-offs, there was substantial variability in the miss rate $(0-20 \%)$ and specificity (47-100\%) when each study used its lowest limit of quantification (Supplementary Fig. 5). The variability remained when standardising to the same $10 \mu \mathrm{g} / \mathrm{g}$ cut-off (Supplemental Fig. 6). We, therefore, focussed on the nine contemporary studies (with at least ten CRC cases) conducted in the United Kingdom that only recruited patients between 2015 and 2020, and all via the same national cancer referral pathway (NICE NG12) to provide consistency. All nine studies (35,925 patients in total, including 1088 with CRC) used one of the FIT analysers recommended by NICE DG30 (OC-Sensor or HM-JACKarc) [30]. The pooled CRC miss rate is $8.7 \%$ and pooled specificity $77.1 \%$, using the lowest limit of quantification reported for each study (Fig. 2), with corresponding estimates of 9.7 and $76.4 \%$ when the same $10 \mu \mathrm{g} / \mathrm{g}$ cut-off was used in all studies (Supplementary Fig. 7). Even among this apparently homogenous group of studies, variability in the accuracy of FIT is observed that is unlikely to all be due to differences in testing methodologies and analyser-specific cut-offs (the CRC miss rate ranged from 2.5 to $20 \%$, and specificity 47.0 to 77.9\%; Fig. 2). The heterogeneity is statistically significant.

Using the QUADAS-2 instrument for assessing study quality (risk of bias and applicability), all nine UK studies had a low risk of bias for almost all of the attributes (Supplementary Table 8). Therefore, subgroup analyses based on quality were not necessary.

In response to the variation in FIT cut-off values between the UK studies, we additionally focussed on the four studies that reported results for $\mathrm{f}-\mathrm{Hb}<4 \mu \mathrm{g} / \mathrm{g}$. The pooled CRC miss rate and specificity were $7.2 \%$ and $73.8 \%$ respectively (Supplementary Fig. 8 ), based on 14,790 patients in total and 494 CRC cases. 
Table 1. Patient characteristics.

\begin{tabular}{|c|c|c|c|}
\hline \multirow[t]{2}{*}{ Characteristics } & \multicolumn{3}{|l|}{ Cancer outcome } \\
\hline & Total, $N=3596$ & $\begin{array}{l}\text { Any cancer, } \\
N=97\end{array}$ & $\begin{array}{l}\text { No cancer found, } \\
N=3499\end{array}$ \\
\hline $\begin{array}{l}\text { Median age, years } \\
\text { (range; IQR) }\end{array}$ & 67 (19-99; 57-75) & $71(34-92 ; 63-78)$ & $67(19-99 ; 57-75)$ \\
\hline \multicolumn{4}{|c|}{ Age group, years (\%) } \\
\hline$<30$ & $21(0.6)$ & $0(0)$ & $21(0.6)$ \\
\hline 30-39 & $79(2.2)$ & $2(2.1)$ & $77(2.2)$ \\
\hline $40-49$ & $262(7.3)$ & $1(1.0)$ & $261(7.5)$ \\
\hline $50-59$ & $739(20.6)$ & $13(13.4)$ & $726(20.7)$ \\
\hline $60-69$ & $979(27.2)$ & $24(24.7)$ & $955(27.3)$ \\
\hline $70-79$ & $1016(28.3)$ & $41(42.3)$ & $975(27.9)$ \\
\hline $80-89$ & $476(13.2)$ & $14(14.4)$ & $462(13.2)$ \\
\hline $90+$ & $24(0.7)$ & $2(2.1)$ & $22(0.6)$ \\
\hline Missing data & N/A & N/A & N/A \\
\hline \multicolumn{4}{|l|}{ Sex, number (\%) } \\
\hline Female & $1911(53.1)$ & $40(41.2)$ & $1871(53.5)$ \\
\hline Male & $1675(46.6)$ & $56(57.7)$ & $1619(46.3)$ \\
\hline Missing data & $10(0.3)$ & $1(1.0)$ & $9(0.3)$ \\
\hline \multicolumn{4}{|c|}{ Age group of females, number (\%) } \\
\hline$<30$ & $12(0.3)$ & $0(0)$ & $12(0.3)$ \\
\hline $30-49$ & $182(5.1)$ & $2(2.1)$ & $180(5.1)$ \\
\hline $50-79$ & $1460(40.6)$ & $31(32.0)$ & $1429(40.8)$ \\
\hline $80+$ & $257(7.1)$ & $7(7.2)$ & $250(7.1)$ \\
\hline Missing data & $\mathrm{N} / \mathrm{A}$ & N/A & N/A \\
\hline \multicolumn{4}{|c|}{ Age group of males, number (\%) } \\
\hline$<30$ & $9(0.3)$ & $0(0)$ & $9(0.25)$ \\
\hline $30-49$ & $159(4.4)$ & $1(1.0)$ & $158(4.5)$ \\
\hline $50-79$ & $1267(35.2)$ & $46(47.4)$ & $1221(34.9)$ \\
\hline $80+$ & $240(6.7)$ & $9(9.3)$ & $231(6.6)$ \\
\hline Missing data & N/A & N/A & N/A \\
\hline \multicolumn{4}{|c|}{ Ethnicity, number (\%) } \\
\hline $\begin{array}{l}\text { Black/Black } \\
\text { British }\end{array}$ & $163(4.5)$ & $6(6.2)$ & $157(4.5)$ \\
\hline $\begin{array}{l}\text { Asian/Asian } \\
\text { British }\end{array}$ & $220(6.1)$ & $1(1.0)$ & $219(6.3)$ \\
\hline Other Asian ${ }^{a}$ & $73(2.0)$ & $3(3.1)$ & $70(2.0)$ \\
\hline White & $845(23.5)$ & $25(25.8)$ & $820(23.4)$ \\
\hline British mixed & $645(17.9)$ & $18(18.6)$ & $627(17.9)$ \\
\hline Multiple/other & $200(5.6)$ & $3(3.1)$ & $197(5.6)$ \\
\hline Missing data & $1450(40.3)$ & $41(42.3)$ & $1409(40.3)$ \\
\hline
\end{tabular}

'The ethnicity of 'Other Asian' consisted of those with Chinese ethnicity or Asian ethnicity other than Indian/Indian British, Pakistani/Pakistan British or Bangladeshi/Bangladeshi British.

\section{DISCUSSION}

We report the results of a large study evaluating the use of FIT in people presenting with high-risk symptoms of bowel cancer, presenting the data in the context of a literature review and updated meta-analyses. The aim was to examine the contemporary evidence on whether FIT can as act as an effective 'rule-out' tool for CRC, allowing clinicians to triage patients with colorectal symptoms into a high-risk group warranting urgent investigation, and a lower risk group that could be given some reassurance and possibly further monitoring.

In our study, the lowest $\mathrm{f}-\mathrm{Hb}$ threshold $(<4 \mu \mathrm{g} / \mathrm{g})$ would miss one in eight CRC cases, but with high specificity (73\%), and at $<10$ $\mu \mathrm{g} / \mathrm{g}$, one in six CRC cases could be missed. We showed that $\mathrm{f}-\mathrm{Hb}$ concentrations were not materially associated with age, sex or ethnicity as also seen in other studies of symptomatic patients [26], but unlike studies of asymptomatic people [43-45].

NPV is often reported as a measure of test performance for ruleout tests. However, very high NPVs can be due to having a large number of non-cancer patients in relation to a small number of CRC cases, particularly in small studies. The NPV in our study was
99.6\% for $\mathrm{f}-\mathrm{Hb}<4 \mu \mathrm{g} / \mathrm{g}$, similar to other studies, but this masks that as many as $12 \%$ of cancers would be missed. High NPVs, therefore, give false reassurance about the effectiveness of the FIT test in ruling out CRC.

The nine studies recently conducted in the United Kingdom (Fig. 2) produce a pooled CRC miss rate of $8.7 \%$ and specificity of $77.1 \%$ (i.e. identifies people without cancer who might be able to avoid further investigations, unless there are other clinical indications for a referral, such as persistent symptoms, despite having a low $\mathrm{f}-\mathrm{Hb}$ ); the corresponding estimates were 7.2 and $74 \%$ in the four studies that used $\mathrm{f}-\mathrm{Hb}<4 \mu \mathrm{g} / \mathrm{g}$. Our own study values were approximately in the middle of the range across all studies (Fig. 2). Reasons for the variability in the CRC miss rate could include patient characteristics and the use of reference standards in addition to colonoscopy. However, when we focussed only on recent UK studies, reasons for the variability were not evident from the publications. All assay methods are recommended by NICE and because these UK studies recruited from patients on the NG12 referral pathway, it is unexpected that they would be fundamentally different. Among the four studies that reported data for $\mathrm{f}-\mathrm{Hb}$ $<4 \mu \mathrm{g} / \mathrm{g}$ including our own $[8,26,39]$, patient characteristics were similar (Supplementary Table 6), and although the percentage of CRC cases found varied between 2.5 and $6.2 \%$, these are consistent with the expected $2-8 \%$ using symptoms alone in the United Kingdom [46, 47]. The study by D'Souza et al. [26] was based on patients who had a colonoscopy, whereas our study included patients who had any investigation as part of the referral, which might partly explain the difference in the CRC miss rates and specificity. However, when we only examined patients who had a colonoscopy in our study, the CRC miss rate and specificity at $\mathrm{f}-\mathrm{Hb}<4 \mu \mathrm{g} / \mathrm{g}$ were $10 \%$ and $74 \%$, respectively, which was still different from 3 and $65 \%$ in D'Souza et al. [26]. It is likely, therefore, that the variability in FIT test performance we observed largely reflects the natural variability (chance) often seen in metaanalyses in medical research.

Our study used the OC-Sensor ${ }^{\mathrm{TM}} \mathrm{iO}$, which is one of the recommended analysers in the NICE DG30 guidance [30], with a lower limit of quantification of $4 \mu \mathrm{g} / \mathrm{g}$. NICE suggests that the three recommended analysers are comparable. However, there are differences in analytical performance [48] which may affect the generalisability of results between studies. The relevance of this is unknown, but it is a potential consideration. In our study, the $7.7 \%$ coefficient of variation at the lowest limit of detection appears to be higher than that expected at higher $\mathrm{f}-\mathrm{Hb}$ thresholds, so it is possible that differences in test performance might be greater at low thresholds.

Our study is important because participants were not restricted by the type of examination performed on the urgent CRC pathway; they were drawn from a wide geography representing a diverse demographic across primary and secondary care. The cancer investigations were representative of pragmatic clinical practice; for example, the increased use of CT colonography for those over 80 years of age.

Our results suggest that patient symptoms (the presence of abdominal pain or anaemia at the time of referral) might be of use when considered alongside a negative FIT result. Abdominal pain is a common symptom, but in the context of a high-risk referral pathway, an obstructive cause may make it more worrisome. Other prospective studies [22,42] and cohort studies [8,49] have identified the same association of anaemia with FIT in the diagnosis of patients with CRC. Nevertheless, in our study, abdominal pain and anaemia were recorded once at the time of referral. If the practice were to change, it would need to be ascertained whether these clinical factors were persistent or not, and how this may influence the clinical decision to refer for cancer investigations.

Our study had a few limitations. First, $2.9 \%$ of our samples were unsuitable for FIT analysis. This is in line with previous discussions 
Table 2. Test performance of FIT for colorectal cancer (CRC) at different f-Hb cut-offs.

\begin{tabular}{|c|c|c|c|c|c|c|c|c|c|}
\hline \multicolumn{6}{|c|}{ Individuals with negative test results, i.e. below the specified f-Hb cut-off } & \multicolumn{4}{|c|}{$\begin{array}{l}\text { Individuals with positive test results, i.e. at or above the specified } \\
\text { f-Hb cut-off }\end{array}$} \\
\hline $\begin{array}{l}\text { f-Hb cut- } \\
\text { off }(\mu g / g)\end{array}$ & $\begin{array}{l}\text { Not cancer } \\
\text { (specificity)* } \\
(n=3499) \text { (TN) }\end{array}$ & $\begin{array}{l}\text { Colorectal } \\
\text { cancer*\# } \\
(n=90) \text { (FN) }\end{array}$ & $\begin{array}{l}\text { Negative predictive } \\
\text { value }(\%) \\
\text { (TN/TN + FN) }\end{array}$ & $\begin{array}{l}\text { Risk of CRC } \\
\text { among test } \\
\text { negatives, } \\
\text { (FN/TN + FN) }\end{array}$ & $\begin{array}{l}\% \text { of all patients } \\
\text { beneath } \\
\text { threshold } \\
(N=3596)\end{array}$ & $\begin{array}{l}\text { f-Hb cut- } \\
\text { off }(\mu g / g)\end{array}$ & $\begin{array}{l}\text { Sensitivity } \\
(n=90 \\
\text { colorectal } \\
\text { cancers)* (TP) }^{*}\end{array}$ & $\begin{array}{l}\text { False-positive } \\
\text { rate* } \\
(n=3499) \text { (FP) }\end{array}$ & $\begin{array}{l}\text { Positive } \\
\text { predictive } \\
\text { Value (\%) } \\
\text { (TP/TP + FP) }\end{array}$ \\
\hline & No. (\%) & No. (\%) & $\%$ & No. per 1000 & $\%$ & & $\%$ (no.) & $\%$ (no.) & $\%$ \\
\hline$<4$ & $2556(73.0)$ & $11(12.2)$ & 99.6 & 4.3 & 71.4 & $\geq 4$ & $87.8(79)$ & $27.0(943)$ & 7.7 \\
\hline$<6$ & $2662(76.1)$ & $12(13.3)$ & 99.6 & 4.5 & 74.4 & $\geq 6$ & $86.7(78)$ & $23.9(837)$ & 8.5 \\
\hline$<10$ & $2803(80.1)$ & $15(16.7)$ & 99.5 & 5.3 & 78.5 & $\geq 10$ & $83.3(75)$ & 19.9 (696) & 9.7 \\
\hline$<20$ & $2993(85.5)$ & $17(18.9)$ & 99.4 & 5.6 & 83.8 & $\geq 20$ & $81.1(73)$ & $14.5(506)$ & 12.6 \\
\hline$<50$ & 3205 (91.6) & $23(25.6)$ & 99.3 & 7.1 & 89.9 & $\geq 50$ & $74.4(67)$ & 8.4 (294) & 18.6 \\
\hline$<80$ & 3265 (93.3) & $29(32.2)$ & 99.1 & 8.8 & 91.7 & $\geq 80$ & $67.8(61)$ & 6.7 (234) & 20.7 \\
\hline$<100$ & $3294(94.1)$ & 32 (35.6) & 99.0 & 9.6 & 92.6 & $\geq 100$ & $64.4(58)$ & $5.9(205)$ & 22.1 \\
\hline$<120$ & 3315 (94.7) & 35 (38.9) & 99.0 & 10.4 & 93.3 & $\geq 120$ & $61.1(55)$ & $5.3(184)$ & 23.0 \\
\hline$<150$ & $3331(95.2)$ & $38(42.2)$ & 98.9 & 11.3 & 93.8 & $\geq 150$ & $57.8(52)$ & $4.8(168)$ & 23.6 \\
\hline$<200$ & 3347 (95.7) & 41 (45.6) & 98.8 & 12.1 & 94.4 & $\geq 200$ & $54.4(49)$ & $4.3(152)$ & 24.4 \\
\hline
\end{tabular}

*Excludes 7 patients with cancer other than CRC.

\#This is 100 minus sensitivity.

False-positive rate is the same as 100 minus specificity.

$T N$ true negatives, FN False negatives, TP True positives, FP False positives.

Table 3. Distribution of selected clinical features among individuals with and without $\mathrm{CRC}$ at $\mathrm{f}-\mathrm{Hb}<10 \mu \mathrm{g} / \mathrm{g}$ (false negatives).

\begin{tabular}{|c|c|c|c|}
\hline Clinical features & $\begin{array}{l}\text { With CRC, } \\
N=15(\%)\end{array}$ & $\begin{array}{l}\text { Without CRC, } \\
N=2803(\%)\end{array}$ & $P$ value ${ }^{a}$ \\
\hline Anaemia & $8(53.3)$ & $502(17.9)$ & 0.002 \\
\hline Abdominal pain & $6(40.0)$ & $355(12.7)$ & 0.008 \\
\hline $\begin{array}{l}\text { Either abdominal pain } \\
\text { or anaemia }\end{array}$ & $10(66.7)$ & $825(29.4)$ & 0.003 \\
\hline $\begin{array}{l}\text { Both abdominal pain } \\
\text { and anaemia }\end{array}$ & $2(13.3)$ & $16(0.6)$ & 0.004 \\
\hline $\begin{array}{l}\text { Neither pain nor } \\
\text { anaemia }\end{array}$ & $3(20.0)$ & $1962(70.0)$ & $<0.001$ \\
\hline $\begin{array}{l}\text { Change in } \\
\text { bowel habit }\end{array}$ & $9(60.0)$ & $1506(53.7)$ & 0.80 \\
\hline Rectal bleeding & $4(26.7)$ & $691(24.7)$ & 0.77 \\
\hline Weight loss & $1(6.7)$ & $246(8.8)$ & $>0.99$ \\
\hline Family history of CRC & $1(6.7)$ & $66(2.4)$ & 0.30 \\
\hline Abnormal imaging & $1(6.7)$ & $33(1.2)$ & 0.17 \\
\hline $\begin{array}{l}\text { Previous } \\
\text { bowel cancer }\end{array}$ & $1(6.7)$ & $0(0)$ & - \\
\hline
\end{tabular}

${ }^{a}$ Fisher's exact test.

At $<4 \mu \mathrm{g} / \mathrm{g}, 3 \mathrm{CRC}$ cases had neither abdominal pain nor anaemia, as did 1793 people without cancer $(p<0.001)$.

over stool self-sampling issues, such as delay in posting the sample back [50] or sampling the stool [51]. Only a single stool sample was requested from each patient, and Högberg et al. indicate that this could lead to missing one-tenth of symptomatic CRCs [52], compared to using three samples, while other studies did not find any significant improvement in test accuracy when two FITs were performed [23, 38]. Second, ethnicity data were not recorded for $40 \%$ of patients, although the percentage was similar between patients with and without cancer and thus may not have introduced bias. Third, a final clinical diagnosis was not recorded on the study case report forms for 696 patients during the study period. However, their exclusion would not have affected the results because their characteristics were similar to those included in the analyses (e.g. among the 696 patients, 79\% had $\mathrm{f}-\mathrm{Hb}$ $<10 \mu \mathrm{g} / \mathrm{g}$ and $50 \%$ were male, with corresponding figures of 78 and $47 \%$ among those included in the analyses). Nevertheless, with 3596 patients (90 CRC cases) we clearly exceeded our target sample size of 2200 ( 80 cases). Fourth, we focus on the performance of FIT as a single rule-out test on its own, as specified in the study protocol and because it can be interpreted easily. Further statistical analyses are planned to attempt to develop a CRC prediction model using various parameters considered together (FIT, clinical symptoms and biochemical results such as haemoglobin).

Our study was performed in the context of considering largely symptom-based criteria for cancer referral. The current criteria for referral, which has an approximate 3\% cancer rate, necessarily mean large numbers of patients referred will have normal test results, even allowing for other significant findings such as IBD or adenomas. Data from our study and the meta-analyses demonstrate that employing FIT as a triage tool can target unpleasant and potentially harmful investigations for patients who would most benefit. This represents a significant saving in healthcare resources and would address the problem of many referrals that are currently seen, which overburdens endoscopy and radiology departments without substantially improving the CRC diagnostic rate [53].

It is important to acknowledge that using FIT alone at any threshold can miss CRC cases, which would be found by the NG12 referral pathway, and that the magnitude of the miss rate varies between studies. Practical clinical use of FIT as a triage tool will clearly be hampered by concerns of both clinicians and patients about missed cancers (false-negative FIT). In the absence of a validated clinical risk score, a second clinical review could allow reassessment of the patient. Our study does not provide definitive guidance of how this safety netting should be conducted, or whether it should be in primary or secondary care. Clinicians and researchers should develop risk assessment tools for use in safety netting to minimise the number of missed CRCs. The (post hoc) analysis from our study that the presence of multiple clinical features, particularly anaemia or abdominal pain, appear to be more common in cancers with FIT below the threshold would suggest repeating a full blood count along with clinical reassessment would be appropriate. However, further studies are needed to confirm this. Demonstrating a decrease in haemoglobin, alongside additional clinical features, could be used to consider the patient for urgent referral. Further studies should evaluate the value of repeat FIT if symptoms persist.

NICE guidance in England currently recommends the use of FIT to triage 'low-' risk patients (those who do not meet the urgent 


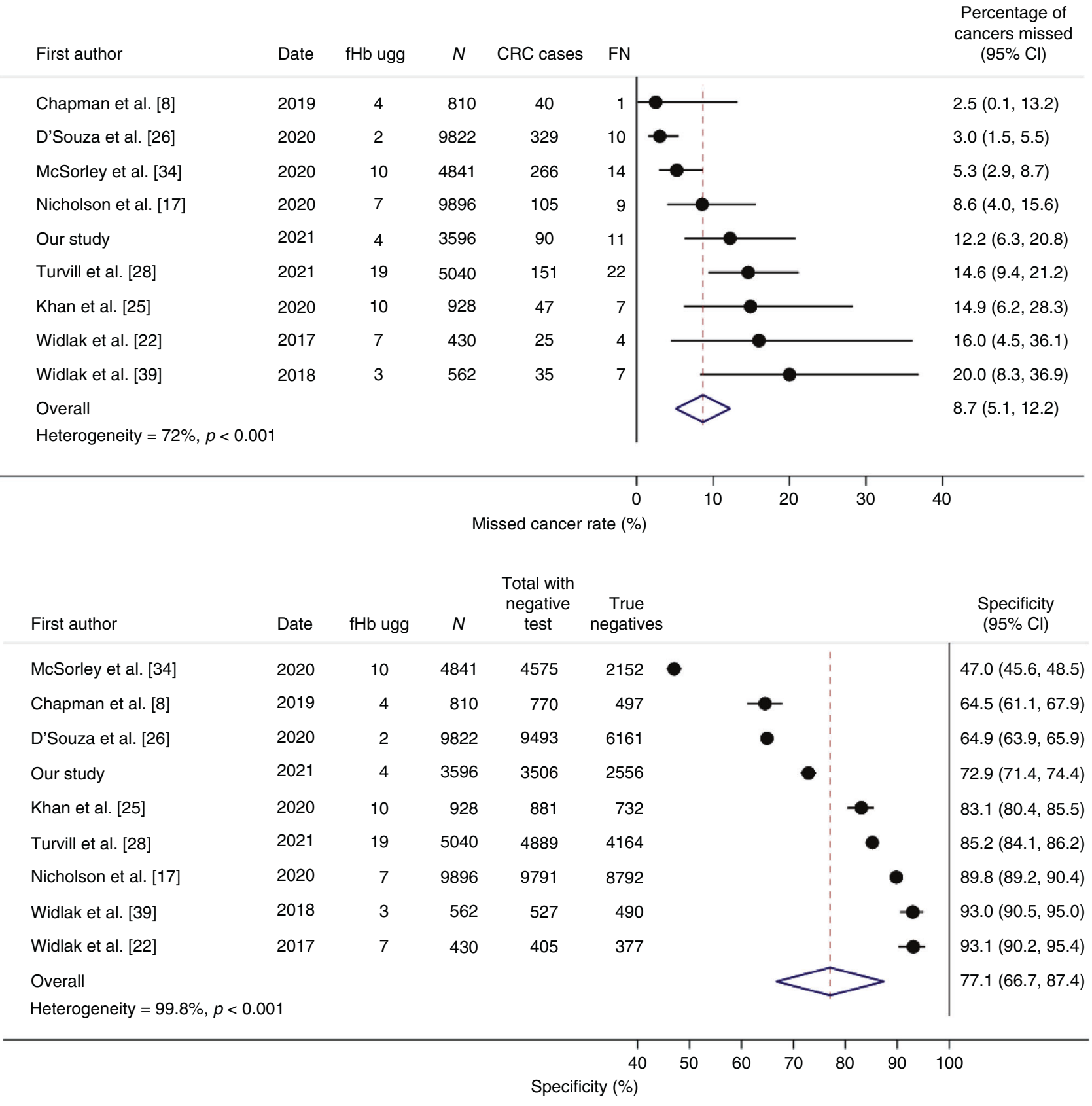

Fig. 2 Nine studies were conducted in the United Kingdom (patients recruited between 2015 and 2020), in which all patients were referred using the NICE NG12 pathway. CRC miss rate (100 minus sensitivity), and specificity using the lowest limit of detection for f-Hb in each study. Excluding McSorley et al. (because it had a noticeably low specificity), the pooled specificity is $80.8 \%(95 \% \mathrm{Cl} 72.5-89.1)$. The OCSensor FIT assay was used in Chapman et al. [8] and our own study, and all others used HM-JACKarC; 1088 CRC cases. $N$ total number of patients in each study, FN false negatives.

CRC pathway referral criteria) presenting with lower abdominal symptoms in primary care [30], where an $\mathrm{f}-\mathrm{Hb}$ concentration of $\geq 10 \mu \mathrm{g} / \mathrm{g}$ can be used to justify an urgent referral. We provide further evidence on the value of FIT in a higher-risk symptomatic group.

To conclude, we demonstrate that FIT is an effective triage tool with an estimated CRC miss rate of 1 in 14 from the meta-analysis (or 1 in 8 from our own study) for patients presenting with highrisk symptoms of CRC, while a substantial proportion of people without cancer (up to 3 in 4) might be able to avoid urgent investigations, depending on whether they are referred for other symptoms (e.g. clinical suspicion) regardless of their FIT level. FIT, therefore, has the ability to focus urgent diagnostic investigations on the patients most likely to have a CRC diagnosis. However, whilst effectively identifying patients for urgent cancer investigation, the use of FIT may also lead to many people without cancer avoiding investigations such as colonoscopy. This should improve the targeted allocation of healthcare resources. However, these benefits should not come at the expense of delaying the diagnosis of patients with CRC who present with symptoms, but have low FIT levels. Further work is needed to inform patients and clinicians of the necessary safety netting so that any FIT based referral guidance is as effective in case finding for CRC as the system it replaces. 


\section{DATA AVAILABILITY}

Anonymised data will be shared on reasonable request to the corresponding author.

\section{REFERENCES}

1. Office for National Statistics. Cancer survival by stage at diagnosis for England (experimental statistics): adults diagnosed 2012, 2013 and 2014 and followed up to 2015. 2016. https://www.ons.gov.uk/peoplepopulationandcommunity/healthand socialcare/conditionsanddiseases/bulletins/cancersurvivalbystageatdiagnosisfor englandexperimentalstatistics/adultsdiagnosed20122013and2014andfollowed upto2015. Accessed 29 Jan 2020.

2. National Institute for Health and Care Excellence. Suspected cancer: recognition and referral. 2015. https://www.nice.org.uk/guidance/ng12. Accessed 29 Jan 2020.

3. NHS Digital. Cancer Waiting Times Annual Report, 2018-19. 2019. https://www. england.nhs.uk/statistics/statistical-work-areas/cancer-waiting-times/cwt-annualreports/statistical-work-areas-cancer-waiting-times-cwt-annual-reports-cancerwaiting-times-annual-report-2018-19/. Accessed 29 Jan 2020.

4. Mozdiak E, Weldeselassie $Y$, McFarlane M, Tabuso M, Widlak MM, Dunlop A. et al. Systematic review with meta-analysis of over 90000 patients. Does fast-track review diagnose colorectal cancer earlier?. Aliment Pharm Ther. 2019;50:348-72.

5. Digby J, Steele RJC, Strachan JA, Mowat C, Anderson AS, McCann R, et al. Do other variables add value to assessment of the risk of colorectal disease using faecal immunochemical tests for haemoglobin? Ann Clin Biochem. 2019;56:472-9.

6. Vieito NP, Zarraquiños S, Cubiella J. High-risk symptoms and quantitative faecal immunochemical test accuracy: systematic review and meta-analysis. World J Gastroenterol. 2019;25:2383-401.

7. Quyn AJ, Steele RJ, Digby J, Strachan JA, Mowat C, McDonald PJ, et al. Application of NICE guideline NG12 to the initial assessment of patients with lower gastrointestinal symptoms: not FIT for purpose? Ann Clin Biochem. 2018;55:69-76.

8. Chapman C, Bunce J, Oliver S, Ng O, Tangri A, Rogers R, et al. Service evaluation of faecal immunochemical testing and anaemia for risk stratification in the 2-weekwait pathway for colorectal cancer. BJS Open. 2019;3:395-402.

9. Lee JK, Liles EG, Bent S, Levin TR, Corley DA. Accuracy of fecal immunochemical tests for colorectal cancer: Systematic review and meta-analysis. Ann Intern Med. 2014;160:171-81.

10. Cross AJ, Wooldrage K, Robbins EC, Kralj-Hans I, MacRae E, Piggott C, et al. Faecal immunochemical tests (FIT) versus colonoscopy for surveillance after screening and polypectomy: a diagnostic accuracy and cost-effectiveness study. Gut. 2019;68:1642-52.

11. Stonestreet J, Chandrapalan S, Woolley D, Uthman O, Arasaradnam RP. Systematic review and meta-analysis: diagnostic accuracy of faecal immunochemical testing for haemoglobin (FIT) in detecting colorectal cancer for both symptomatic and screening population. Acta Gastroenterol Belg. 2019;82:291-9.

12. Pin-Vieito N, García Nimo L, Bujanda L, Román Alonso B, Gutiérrez-Stampa MÁ, Aguilar-Gama $V$, et al. Optimal diagnostic accuracy of quantitative faecal immunochemical test positivity thresholds for colorectal cancer detection in primary health care: a community-based cohort study. United Eur Gastroenterol J. 2021;9:256-67.

13. Nicholson $B D$, James $T$, East JE, Grimshaw $D$, Paddon $M$, Justice $S$, et al. Experience of adopting faecal immunochemical testing to meet the NICE colorectal cancer referral criteria for low-risk symptomatic primary care patients in Oxfordshire, UK. Frontline Gastroenterol. 2019;10:347-55.

14. D'Souza N, Abulafi M. The faecal immunochemical test in low risk patients with suspected bowel cancer. Br J Hosp Med. 2019;80:22-26.

15. D'Souza N, Hicks G, Benton SC, Abulafi M. The diagnostic accuracy of the faecal immunochemical test for colorectal cancer in risk-stratified symptomatic patients. Ann R Coll Surg Engl. 2020;102:174-9.

16. Juul JS, Hornung N, Andersen B, Laurberg S, Olesen F, Vedsted P. The value of using the faecal immunochemical test in general practice on patients presenting with non-alarm symptoms of colorectal cancer. Br J Cancer. 2018;119:471-9.

17. Nicholson BD, James $T$, Paddon $M$, Justice $S$, Oke JL, East JE, et al. Faecal immunochemical testing for adults with symptoms of colorectal cancer attending English primary care: a retrospective cohort study of 14487 consecutive test requests. Aliment Pharm Ther. 2020;52:1031-41.

18. Ayling RM, Machesney M. Service evaluation of faecal immunochemical testing introduced for use in North East London for patients at low risk of colorectal cancer. J Clin Pathol. 2021;74:163-6.

19. Bailey SER, Abel GA, Atkins A, Byford R, Davies SJ, Mays J, et al. Diagnostic performance of a faecal immunochemical test for patients with low-risk symptoms of colorectal cancer in primary care: an evaluation in the South West of England. Br J Cancer. 2021;124:1231-6.
20. Mowat C, Digby J, Strachan JA, Wilson R, Carey FA, Fraser CG, et al. Faecal haemoglobin and faecal calprotectin as indicators of bowel disease in patients presenting to primary care with bowel symptoms. Gut. 2016;65:1463-9.

21. Godber IM, Todd LM, Fraser CG, MacDonald LR, Younes HB. Use of a faecal immunochemical test for haemoglobin can aid in the investigation of patients with lower abdominal symptoms. Clin Chem Lab Med. 2016;54:595-602.

22. Widlak MM, Thomas CL, Thomas MG, Tomkins C, Smith S, O'Connell N, et al. Diagnostic accuracy of faecal biomarkers in detecting colorectal cancer and adenoma in symptomatic patients. Aliment Pharm Ther. 2017;45:354-63.

23. Turvill J, Mellen S, Jeffery L, Bevan S, Keding A, Turnock D. Diagnostic accuracy of one or two faecal haemoglobin and calprotectin measurements in patients with suspected colorectal cancer. Scand J Gastroenterol. 2018;53:1526-34.

24. Farrugia A, Widlak M, Evans C, Smith SC, Arasaradnam R. Faecal immunochemical testing (FIT) in symptomatic patients: What are we missing? Frontline Gastroenterol. 2020;11:28-33.

25. Khan AA, Klimovskij M, Harshen R. Accuracy of faecal immunochemical testing in patients with symptomatic colorectal cancer. BJS Open. 2020;4:1180-8.

26. D'Souza N, Delisle TG, Chen M, Benton S, Abulafi M, Warren O, et al. Faecal immunochemical test is superior to symptoms in predicting pathology in patients with suspected colorectal cancer symptoms referred on a $2 \mathrm{WW}$ pathway: a diagnostic accuracy study. Gut. 2021;70:1130-8.

27. Rodríguez-Alonso L, Rodríguez-Moranta F, Ruiz-Cerulla A, Lobatón T, Arajol C, Binefa $G$, et al. An urgent referral strategy for symptomatic patients with suspected colorectal cancer based on a quantitative immunochemical faecal occult blood test. Dig Liver Dis. 2015;47:797-804.

28. Turvill J, Turnock D, Cottingham D, Haritakis M, Jeffery L, Girdwood A, et al. The Fast Track FIT study: diagnostic accuracy of faecal immunochemical test for haemoglobin in patients with suspected colorectal cancer. Br J Gen Pract. 2021. https://doi.org/10.3399/BJGP.2020.1098.

29. Westwood M, Corro Ramos I, Lang S, Luyendijk M, Zaim R, Stirk L, et al. Faecal immunochemical tests to triage patients with lower abdominal symptoms for suspected colorectal cancer referrals in primary care: a systematic review and cost-effectiveness analysis. Health Technol Assess. 2017;21:1-234.

30. National Institute for Health and Care Excellence. Quantitative faecal immunochemical tests to guide referral for colorectal cancer in primary care - Diagnostics guidance [DG30]. 2017. https://www.nice.org.uk/guidance/dg30. Accessed 22 Apr 2020.

31. Cohen JF, Korevaar DA, Altman DG, Bruns DE, Gatsonis CA, Hooft L, et al. STARD 2015 guidelines for reporting diagnostic accuracy studies: explanation and elaboration. BMJ Open. 2016;6:e012799.

32. Cairns SR, Scholefield JH, Steele RJ, Dunlop MG, Thomas HJW, Evans GD, et al. Guidelines for colorectal cancer screening and surveillance in moderate and high risk groups (update from 2002). Gut. 2010;59:666-89.

33. StataCorp. Stata Statistical Software: Release 15. College Station, TX: StataCorp LLC; 2017.

34. McSorley ST, Digby J, Clyde D, Cruickshank N, Burton P, Barker L, et al. Yield of colorectal cancer at colonoscopy according to faecal haemoglobin concentration in symptomatic patients referred from primary care. Colorectal Dis. 2020. https:// doi.org/10.1111/codi.15405.

35. Navarro M, Hijos G, Sostres C, Lué A, Puente-Lanzarote JJ, Carrera-Lasfuentes P, et al. Reducing the cut-off value of the fecal immunochemical test for symptomatic patients does not improve diagnostic performance. Front Med. 2020;7:410. https://doi.org/10.3389/fmed.2020.00410

36. Mattar R, Marques SB, Minata MK, Silva-Etto JMK, Sakai P, De Moura EGH. Diagnostic accuracy of one sample or two samples quantitative fecal immunochemical tests for intestinal neoplasia detection. Arq Gastroenterol. 2020;57:316-22.

37. Högberg C, Gunnarsson U, Jansson S, Thulesius H, Cronberg O, Lilja M. Diagnosing colorectal cancer in primary care: Cohort study in Sweden of qualitative faecal immunochemical tests, haemoglobin levels, and platelet counts. Br J Gen Pract. 2020;70:e843-51.

38. Tsapournas G, Hellström PM, Cao Y, Olsson LI. Diagnostic accuracy of a quantitative faecal immunochemical test vs. symptoms suspected for colorectal cancer in patients referred for colonoscopy. Scand J Gastroenterol. 2020;55:184-92.

39. Widlak MM, Neal M, Daulton E, Thomas CL, Tomkins C, Singh B, et al. Risk stratification of symptomatic patients suspected of colorectal cancer using faecal and urinary markers. Colorectal Dis. 2018;20:0335-42.

40. Högberg C, Karling P, Rutegård J, Lilja M. Diagnosing colorectal cancer and inflammatory bowel disease in primary care: the usefulness of tests for faecal haemoglobin, faecal calprotectin, anaemia and iron deficiency. A prospective study. Scand J Gastroenterol. 2017;52:69-75.

41. Terhaar Sive Droste JS, Oort FA, van der Hulst RWM, van Heukelem HA, Loffeld RJLFvan Turenhoust ST, et al. Higher fecal immunochemical test cutoff levels: Lower positivity rates but still acceptable detection rates for early-stage colorectal cancers. Cancer Epidemiol Biomark Prev. 2011;20:272-80. 
42. Högberg C, Karling P, Rutegård J, Lilja M. Diagnosing colorectal cancer and inflammatory bowel disease in primary care: the usefulness of tests for faecal haemoglobin, faecal calprotectin, anaemia and iron deficiency. A prospective study. Scand J Gastroenterol. 2017;52:69-75.

43. Selby K, Levine EH, Doan C, Gies A, Brenner H, Quesenberry C, et al. Effect of sex, age, and positivity threshold on fecal immunochemical test accuracy: a systematic review and meta-analysis. Gastroenterology. 2019;157:1494-505.

44. McDonald PJ, Strachan JA, Digby J, Steele RJC, Fraser CG. Faecal haemoglobin concentrations by gender and age: implications for population-based screening for colorectal cancer. Clin Chem Lab Med. 2011;50:935-40.

45. Fraser CG, Rubeca T, Rapi S, Chen LS, Chen HH. Faecal haemoglobin concentrations vary with sex and age, but data are not transferable across geography for colorectal cancer screening. Clin Chem Lab Med. 2014;52:1211-6.

46. Pande R, Leung E, McCullough P, et al. Impact of the United kingdom national bowel cancer awareness campaign on colorectal services. Dis Colon Rectum. 2014;57:70-5

47. Vulliamy $P$, McCluney $S$, Raouf $S$, et al. Trends in urgent referrals for suspected colorectal cancer: an increase in quantity, but not in quality. Ann R Coll Surg Engl. 2016;98:564-7.

48. Chapman CJ, Banerjea A, Humes DJ, Allen J, Oliver S, Ford A, et al. Choice of faecal immunochemical test matters: comparison of OC-Sensor and HM-JACKarc, in the assessment of patients at high risk of colorectal cancer. Clin Chem Lab Med. 2020. https://doi.org/10.1515/cclm-2020-1170.

49. Mowat C, Digby J, Strachan JA, McCann R, Hall C, Heather D, et al. Impact of introducing a faecal immunochemical test (FIT) for haemoglobin into primary care on the outcome of patients with new bowel symptoms: a prospective cohort study. BMJ Open Gastroenterol. 2019;6:e000293.

50. Mellen S, de Ferrars M, Chapman C, Bevan S, Turvill J, Turnock D. Evaluation of sample stability for a quantitative faecal immunochemical test and comparison of two sample collection approaches. Ann Clin Biochem. 2018;55:657-64.

51. Godber IM, Benton SC, Fraser CG. Setting up a service for a faecal immunochemical test for haemoglobin (FIT): a review of considerations, challenges and constraints. J Clin Pathol. 2018;71:1041-5.

52. Högberg C, Söderström L, Lilja M. Faecal immunochemical tests for the diagnosis of symptomatic colorectal cancer in primary care: the benefit of more than one sample. Scand J Prim Health Care. 2017;35:369-72.

53. Maclean W, Singh R, Mackenzie P, White D, Benton S, Stebbing J, et al. The twoweek rule colorectal cancer pathway: an update on recent practice, the unsustainable burden on diagnostics and the role of faecal immunochemical testing. Ann R Coll Surg Engl. 2020;102:308-11.

\section{ACKNOWLEDGEMENTS}

The authors would like to thank all participating sites for allocating resources to carry out patient recruitment and follow-up, former data managers Safreena Nazir and James Croft for their data extraction work, Sara Taiyari for recruiting the most participants at multiple sites, Jennifer McGivney, Ed Carbonell, Marcy Madzikanda, Mayada Kaddoura, Dimple Makwana and Hasmita Shivji for the administrative support during the conducting of the study, Aska Matsunaga at NOCLOR for her support in recruiting GP practices and Claire Levermore, Mairead Lyons and Nick Kirby for encouragement and allocation of resources to perform the study as part of the National Cancer Vanguard New Care Models programme. No pre-registration exists for the reported study reported in this article.

\section{AUTHOR CONTRIBUTIONS}

HEL and MM formulated the study design and protocol, and HEL managed the study. ES, RMA, AH and KP-J advised on the study protocol. MM, ES, DC and KP-J conducted a medical review of investigations. RMA and JL conducted the FIT test analysis. MM, ES, CS, RMA, AM, AH, DC and KP-J contributed to the interpretation of results and the critical revision of the manuscript. $\mathrm{AM}$ and $\mathrm{AH}$ conducted the statistical analysis. CS and MM contributed to the recruitment of participants. DC advised on the data management and conducted data cleaning. $\mathrm{HEL}, \mathrm{MM}$ and $\mathrm{AH}$ drafted the initial manuscript. MM was the chief investigator of the study, initiated the study concept and provided oversight and is the guarantor.

\section{FUNDING}

This work was supported by NHS England Cancer Alliance programme (formerly known as the National Cancer Vanguard, part of the New Care Models programme), North London Partners in Health and Care (North Central London's Sustainability and transformation partnership), NIHR University College London Hospitals Biomedical Research Centre and Cancer Research UK and was conducted independently by the North Central London Cancer Alliance (formerly known as UCLH Cancer Collaborative and North Central and East London Cancer Alliance). The Mast Group provided 2000 FIT test tubes. The funding sources had no role in the design, conduct or reporting of the study.

\section{COMPETING INTERESTS}

All authors have completed the ICMJE uniform disclosure form at www.icmje.org/ coi_disclosure.pdf. MM was chair of the NHSE Colorectal Clinical Expert group from October 2014 to February 2020. There are no other relationships or activities that could appear to have influenced the submitted work.

\section{ETHICS APPROVAL AND CONSENT TO PARTICIPATE}

Ethical approval was granted by the UK NRES West Midlands-Solihull Research Ethics Committee (ref. 17/WM/0094) and the Health Research Authority (IRAS/ 213710). The study was performed in accordance with the Declaration of Helsinki.

\section{ADDITIONAL INFORMATION}

Supplementary information The online version contains supplementary material available at https://doi.org/10.1038/s41416-021-01653-x.

Correspondence and requests for materials should be addressed to Helga E. Laszlo.

Reprints and permission information is available at http://www.nature.com/ reprints

Publisher's note Springer Nature remains neutral with regard to jurisdictional claims in published maps and institutional affiliations.

\begin{abstract}
Open Access This article is licensed under a Creative Commons Attribution 4.0 International License, which permits use, sharing, adaptation, distribution and reproduction in any medium or format, as long as you give appropriate credit to the original author(s) and the source, provide a link to the Creative Commons license, and indicate if changes were made. The images or other third party material in this article are included in the article's Creative Commons license, unless indicated otherwise in a credit line to the material. If material is not included in the article's Creative Commons license and your intended use is not permitted by statutory regulation or exceeds the permitted use, you will need to obtain permission directly from the copyright holder. To view a copy of this license, visit http://creativecommons. org/licenses/by/4.0/.
\end{abstract}

(C) The Author(s) 2021 